\title{
Elevated CPW-Fed Slotted Microstrip Antenna for Ultra-Wideband Application
}

\author{
Chandan Kumar Ghosh, ${ }^{1}$ Arabinda Roy, ${ }^{2}$ and Susanta Kumar Parui ${ }^{2}$ \\ ${ }^{1}$ Department of Electronics and Communication Engineering, Dr. B. C. Roy Engineering College, Jemua Road, \\ Fuljhore, Durgapur 713206, India \\ ${ }^{2}$ Department of Electronics and Communication Engineering, Bengal Engineering and Science University, \\ Shibpur, Howrah 711103, India \\ Correspondence should be addressed to Chandan Kumar Ghosh, mcet_ckg@yahoo.com
}

Received 8 June 2012; Revised 17 August 2012; Accepted 8 September 2012

Academic Editor: Karu P. Esselle

Copyright (C) 2012 Chandan Kumar Ghosh et al. This is an open access article distributed under the Creative Commons Attribution License, which permits unrestricted use, distribution, and reproduction in any medium, provided the original work is properly cited.

\begin{abstract}
Elevated-coplanar-waveguide- (ECPW-) fed microstrip antenna with inverted "G" slots in the back conductor is presented. It is modeled and analyzed for the application of multiple frequency bands. The changes in radiation and the transmission characteristics are investigated by the introduction of the slots in two different positions at the ground plane (back conductor). The proposed antenna without slots exhibits a stop band from $2.55 \mathrm{GHz}$ to $4.25 \mathrm{GHz}$ while introducing two slots on the back conductor, two adjacent poles appear at central frequencies of $3.0 \mathrm{GHz}$ and $3.9 \mathrm{GHz}$, respectively, and the antenna shows the ultrawideband (UWB) characteristics. The first pole appears at the central frequency of $3.0 \mathrm{GHz}$ and covers the band width of $950 \mathrm{MHz}$, and the second pole exists at a central frequency of $3.90 \mathrm{GHz}$ covering a bandwidth of $750 \mathrm{MHz}$. Experimental result shows that impedance bandwidth of $129 \%\left(S_{11}<-10 \mathrm{~dB}\right)$ is well achieved when the antenna is excited with both slots. Compared to most of the previously reported ECPW structures, the impedance bandwidth of this antenna is increased and also the size of the antenna becomes smaller and more suitable for many wireless applications like PCS (1850-1990 MHz), WLAN (2.4-2.484 GHz), WiMAX (2.5-2.69 GHz and 5.15-5.85 GHz), and also X-band communication.
\end{abstract}

\section{Introduction}

Recently, a considerable amount of researches have been devoted to the development of UWB antenna for its enabling high data transmission rates, low power consumption, and simple hardware configuration in wireless applications like radio frequency identification devices, sensor networks, radar, location tracking system, and so forth. The UWB antennas of such systems are also required for small size, nondispersive [1], and wideband properties. Its commercial applications of the frequency band from $3.1 \mathrm{GHz}$ to $10.6 \mathrm{GHz}$ were approved by the Federal Communications Commission (FCC) in America in 2002 [2, 3]. As a result, many new UWB antennas [4-12] have been proposed; among them, the printed monopole antennas [13-18] have received much attention due to their wideband characteristic, omnidirectional radiation patterns, high radiation efficiency, and compact size. Recent technological advances and the size reduction of electronic circuits have changed the wireless communications and sensor network design specifications. In particular, they have exposed the need for electrically small antennas that are efficient and have significant bandwidths. The standard electrically small antenna designs are known to be inefficient due to the large reactance and small resistance, which leads to the poor match to a given source. However, to compensate the impedance mismatch and additional bandwidth the researchers have already been introduced the concept of defected ground structure (DGS), defected microstrip structure (DMS), and so forth.

The research in the area of design of compact broadband antenna design for the application of WLAN compatible devices is growing exponentially. For these modern communication applications, size reduction of microstrip patch antenna with wide bandwidth and multiband operation 
TABLE 1: Geometrical parameters of Figure 2.

\begin{tabular}{lccccccccccccc}
\hline Parameters & $L_{0}$ & $L$ & $L_{1}$ & $L_{2}$ & $L_{3}$ & $L_{5}$ & $W_{0}$ & $W$ & $W_{1}$ & $W_{2}$ & $W_{3}$ & $W_{4}$ & $g$ \\
\hline $\mathrm{mm}$ & 8 & 85 & 65 & 28 & 4 & 10 & 16 & 30 & 10 & 12 & 5 & 15 & 1 \\
\hline
\end{tabular}

TABle 2: Geometrical parameters of Figure 3.

\begin{tabular}{lcccccccccccc}
\hline Parameters & $W_{3}$ & $W_{4}$ & $W_{5}$ & $W_{7}$ & $L_{6}$ & $L_{7}$ & $L_{8}$ & $d_{1}$ & $d_{2}=W_{1}$ & $d_{3}$ & $d_{4}$ \\
\hline $\mathrm{mm}$ & 5 & 15 & 0.75 & 3 & 4 & 3 & 1.5 & 7 & 10 & 5 & 7 \\
\hline
\end{tabular}

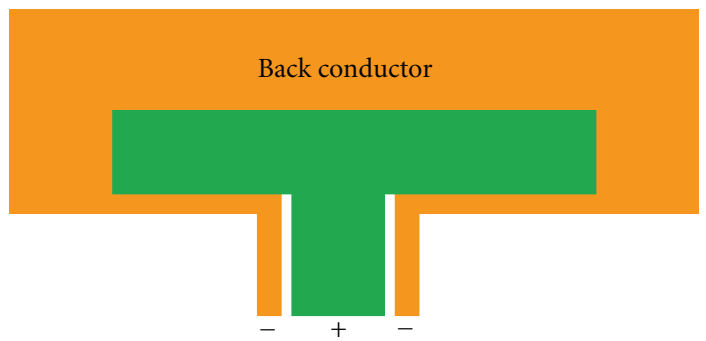

(a)

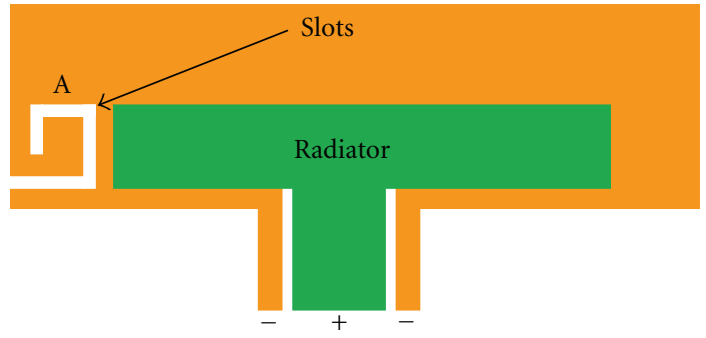

(b)

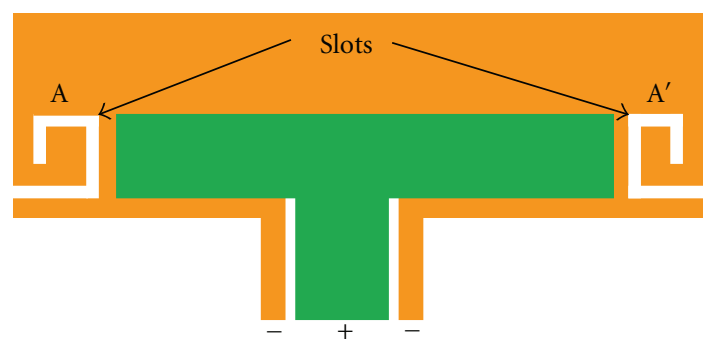

(c)

Figure 1: Geometry of the proposed antenna with (a) no slot, (b) slot (A), and (c) slot $\left(\mathrm{A}^{\prime}\right)$.

are becoming important design considerations for practical applications. Many authors have presented antenna that designs suitable for WLAN operations are in the $2.4 \mathrm{GHz}$ band $(2.4-2.484 \mathrm{GHz})$ and $5.2 / 5.8 \mathrm{GHz}$ bands (5.15-5.35 GHz/5.725-5.825 GHz) [19-22]. Because of the increased demand in wireless communication system, microstrip patch antennas have attracted much interest due to their various attractive feathers. Microstrip antennas with ECPW exhibit attractive performances including significantly wider impedance bandwidth that is not achieved by conventional microstrip configuration.

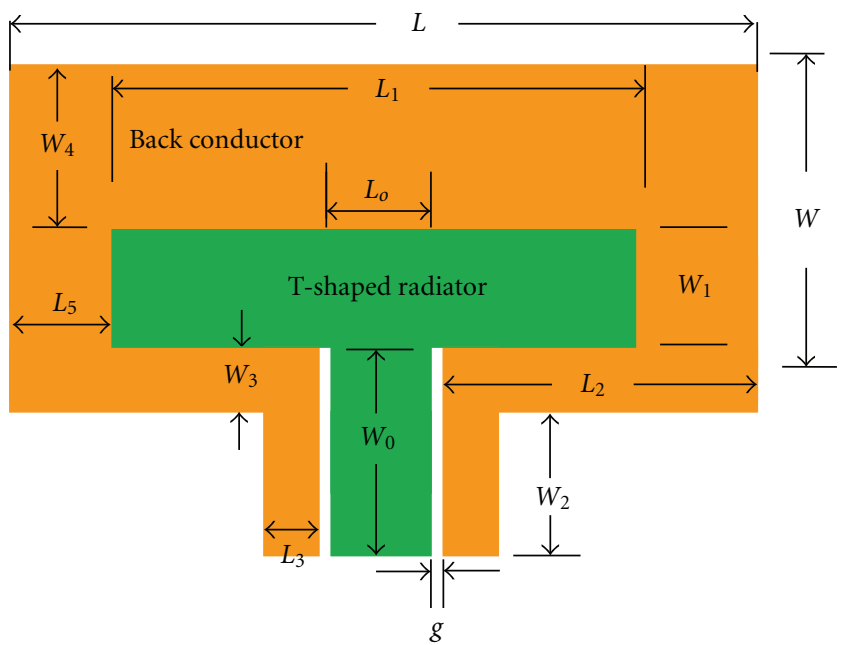

Figure 2: Geometry of the proposed antenna without slots at the ground plane.

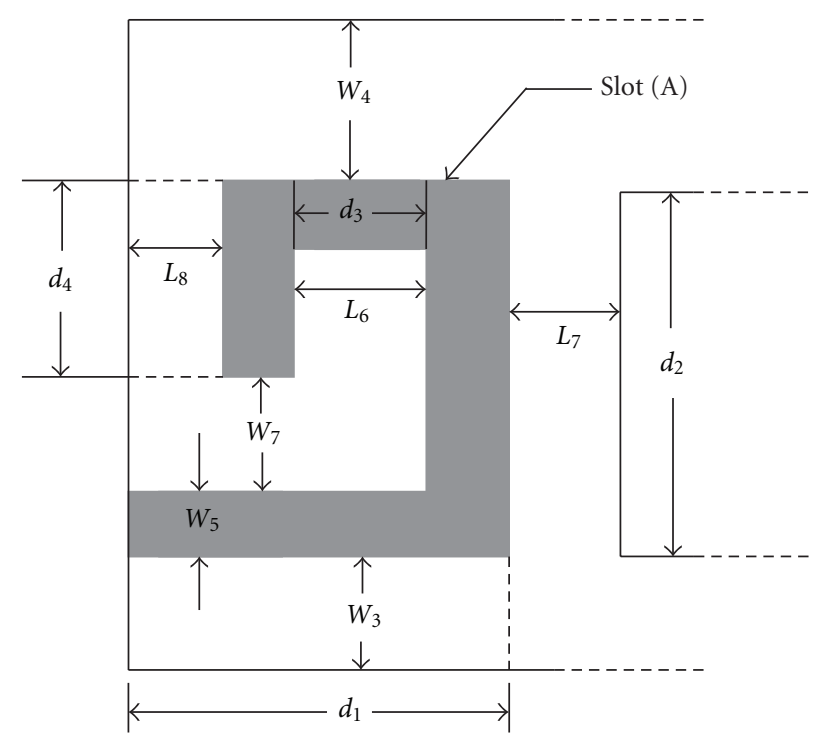

Figure 3: Schematic diagram of inverted “G” slot (A).

In this paper, a simple and compact ECPW-fed microstrip antenna for UWB application is proposed. Few papers have been published in this area [23-31] based on ECPW, but all have insufficient bandwidth or design complicacy. In this design, the proposed antenna offers a bandwidth of $8.74 \mathrm{GHz}(1.85 \mathrm{GHz}$ to $10.54 \mathrm{GHz})$ covering 


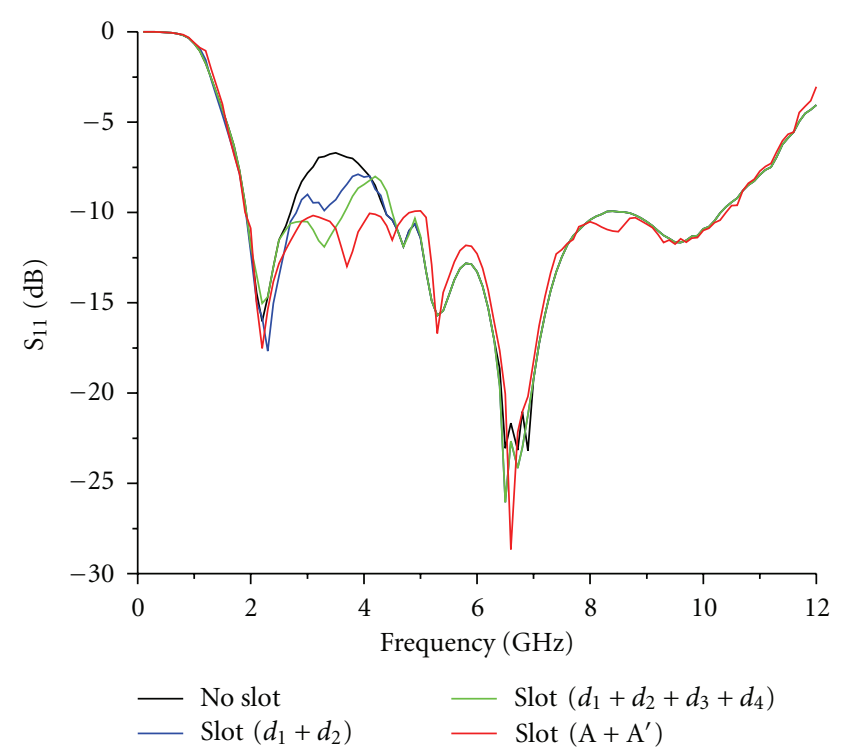

Figure 4: Simulated results of the proposed antenna with and without slots.

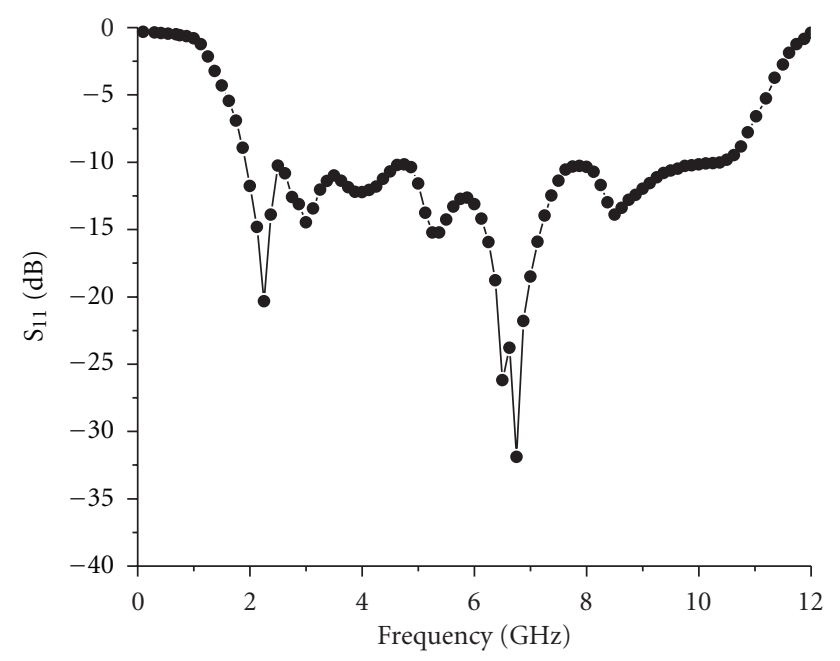

FIgURE 5: Simulated result of $S_{11}$ with slots $\left(A+A^{\prime}\right)$.

FCC regulated band and also PCS $(1.85-1.99 \mathrm{GHz})$ band. The antenna is slotted at the edges of the back conductor (shown in Figure 1) and the effects are studied. This antenna structure has been constructed with less number of design parameters compared with the existing UWB antennas in the literature. The bandwidth, gain, directivity, and other antenna parameters are at acceptable level. IE3D method of moment-based simulation software is used for the analysis. The antenna presented can be easily fabricated and integrated in portable devices. The measured frequency bandwidth with VSWR below 2 of the antenna covers $1.85 \mathrm{GHz}-10.54 \mathrm{GHz}$, which satisfies the UWB system requirement.

The UWB characteristic is achieved by introducing two inverted G-shaped slots on the back conductor as shown in Figure 1. The addition of the slots produces two adjacent

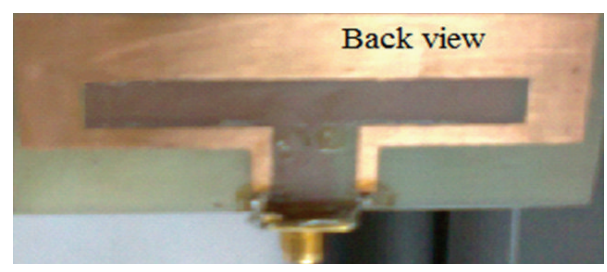

(a)

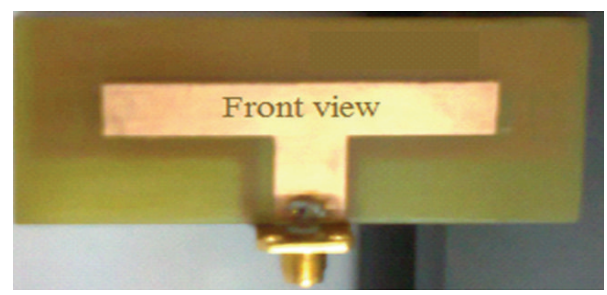

(b)

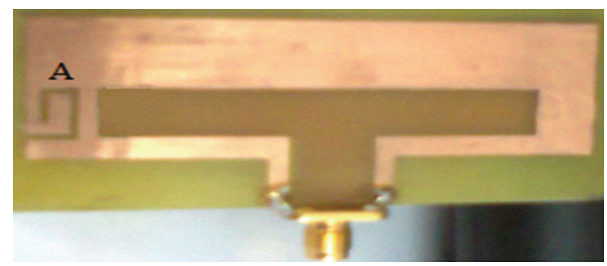

(c)

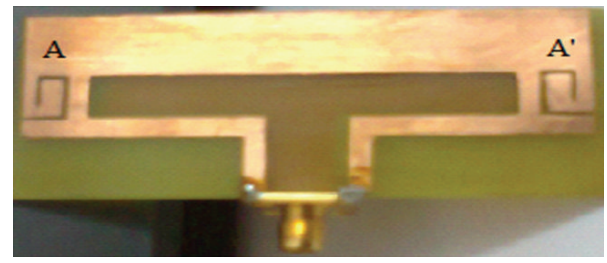

(d)

FIGURE 6: Photograph of the proposed antenna. (a) Back view without slot, (b) front view, (c) back view with slot (A), (d) back view with slot $(\mathrm{A})$ and $\left(\mathrm{A}^{\prime}\right)$.

poles that remove the notch band covering the frequency band ranges from $2.5 \mathrm{GHz}$ to $4.3 \mathrm{GHz}$.

\section{Antenna Design}

In this section, the antenna covering the UWB band is first described. Then the new pass band from $2.5 \mathrm{GHz}$ to $4.3 \mathrm{GHz}$ has been investigated by introducing properly designed two inverted G-slots. The effects of changing the geometric parameters of the proposed antenna on impedance matching and bandwidth are discussed. The UWB antenna design features the gap $(\mathrm{g})$ in both the feed line of the radiator between the radiator and the back conductor which introduces a coupling capacitance and plays an important role in obtaining UWB behavior. Compact UWB antenna and the feeding technique $[32,33]$ are the motivations of this study. The design of the proposed antenna and its experimental results are presented and discussed. Figure 2 shows the geometrical structure without slots and the corresponding dimensions of the proposed antenna are shown in the 


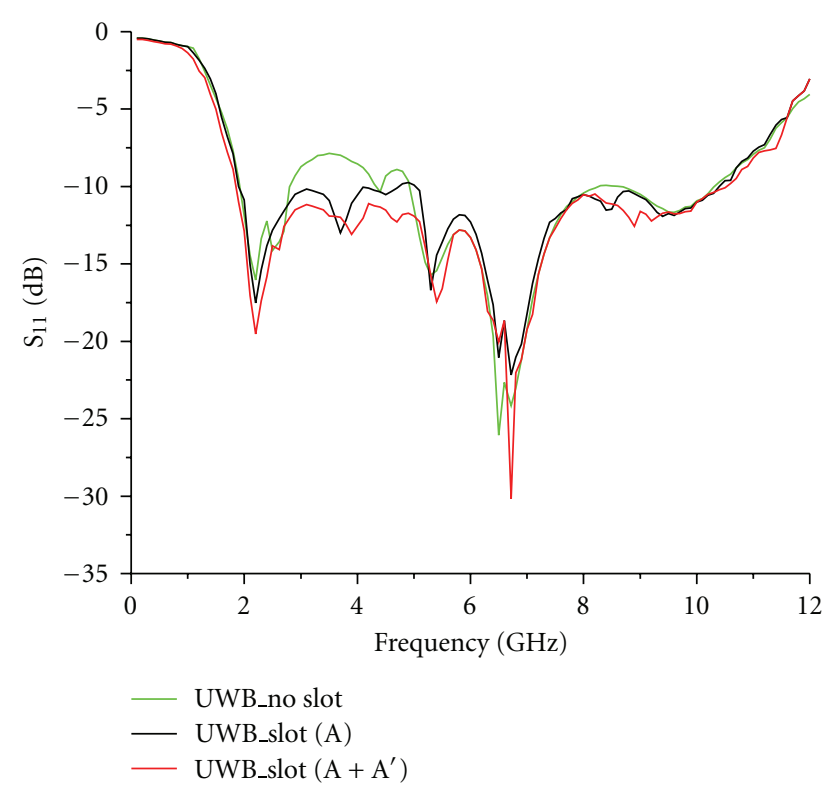

FIgURE 7: Measured results of $S_{11}$ of the proposed antenna.

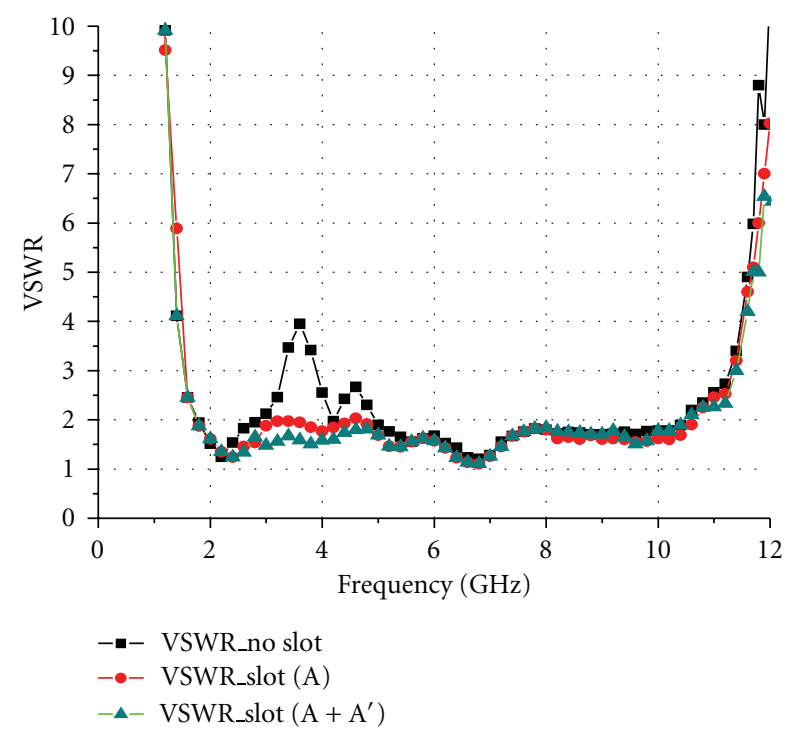

FIGURE 8: Measured results of the variation of VSWR of the proposed antenna.

Table 1 . The antenna is fed by a $50 \Omega$ SMA which is connected to the vertical arm of the T-shaped radiator surrounded by back conductor and guided by two identical gaps (g) of $1.0 \mathrm{~mm}$ width. The antenna is printed on FR4 substrate with the dielectric constant of $\varepsilon r=4.4$, loss tangent of $\delta=.001$, and the substrate thickness of $h=1.587 \mathrm{~mm}$. The slot geometry of the antenna is shown in Figure 3 and its detail dimensions are shown in the Table 2.

The second slot $\left(\mathrm{A}^{\prime}\right)$ is identical to the first one in terms of dimension, and it is placed just to the opposite edge of the back conductor with the similar geometrical position (not shown in the Figure). The introduction of one inverted "G-" shaped slot could not cover the whole FCC-defined UWB

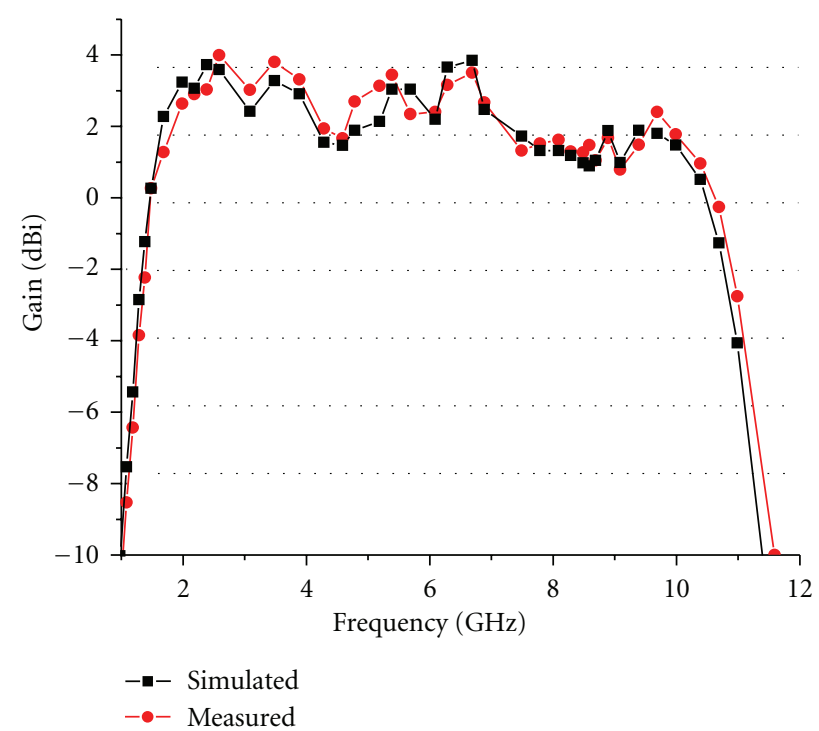

FIGURE 9: Gain versus frequency of the proposed antenna with both slots $(\mathrm{A})$ and $\left(\mathrm{A}^{\prime}\right)$.

frequency band. The addition of second slot $\left(\mathrm{A}^{\prime}\right)$ covers the entire UWB range and it also covers an additional band like PCS $(1850-1990 \mathrm{MHz})$. In fact, the parameters of the tuning arms of slots play an important role for achieving the broadband operation of the proposed antenna. By carefully adjusting the width W5 and length parameters of the slots (A and $\mathrm{A}^{\prime}$ ), the resonance frequency, the lower cutoff, and the higher cut-off frequencies are adjusted. A study of $S_{11}$ versus frequency has been performed by introducing arms $\left(d_{1}, d_{2}\right.$, $d_{3}$, and $d_{4}$ ) of the slot (A) one by one and the effect is studied.

\section{Simulated Results}

To understand the effects of geometric parameters on the frequency responses of the proposed antenna, this study conducts parametric analysis using a MoM-based electromagnetic simulator. This study investigates the effect of dimensions on the antenna characteristics. The important parameters that have optimized in this design are $d_{1}, d_{2}, d_{3}$, $d_{4}, W_{3}, L_{3}, W_{5}, W_{7}, L_{6}, L_{7}, L_{8}$, and $g$. Figure 4 shows the effects of varying the arms of the slot (A) and slot $\left(\mathrm{A}^{\prime}\right)$ on $S_{11}$ parameter.

The simulated result of $S_{11}$ versus frequency of the proposed antenna by introducing the slots $(A)$ and $\left(A^{\prime}\right)$ are shown separately in Figure 5. From VSWR curve, it is observed that VSWR $\leq 2$ for entire UWB range of frequencies when both slots are introduced. The gain versus frequency of the proposed antenna is shown in Figure 7.

From Figure 5, it is observed that the combination of the feed line, the T-shaped radiator, and the slots at the back conductor leads to achieve a large BW. In the antenna structure presented in Figure 1, during several tests and simulations, it was observed that the BW, RL, and the radiation performances of the antenna are principally interrelated to the design of the slots, back conductor, and the shape of the radiator. 


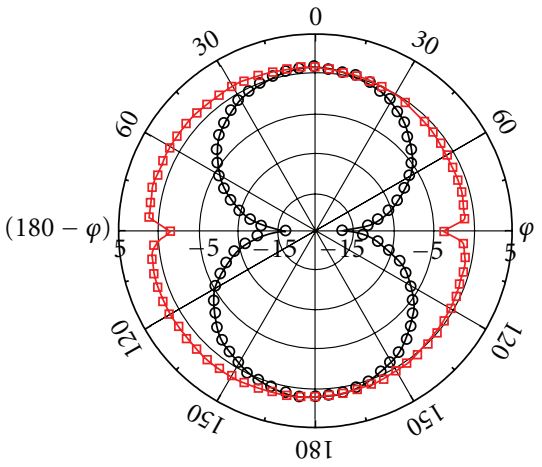

(a)

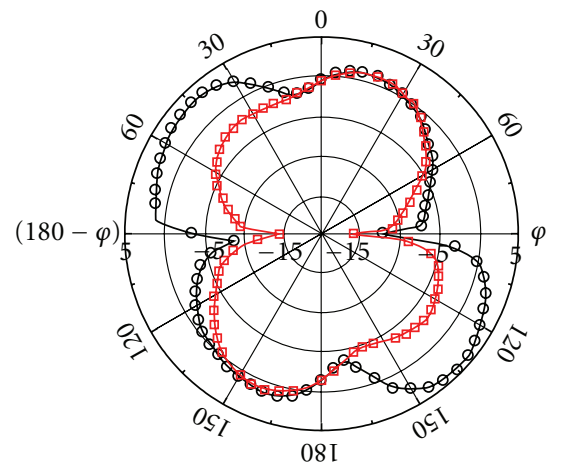

(d)

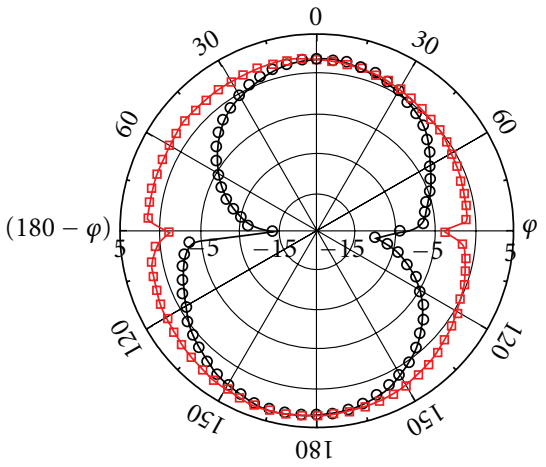

(b)

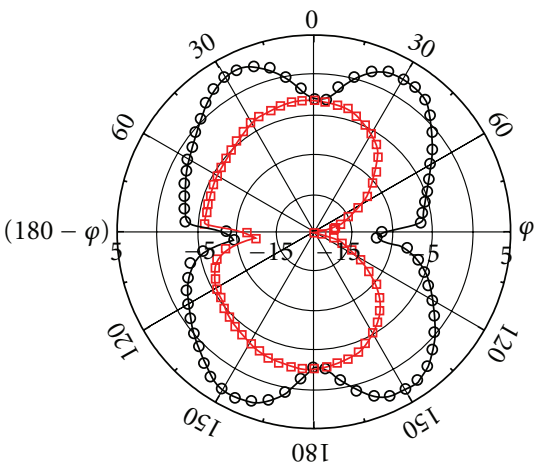

(e)

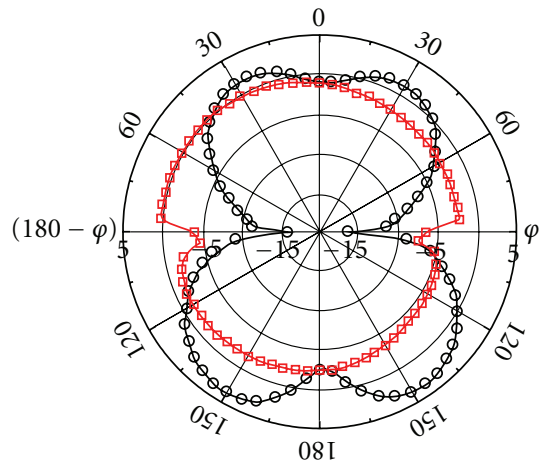

(c)

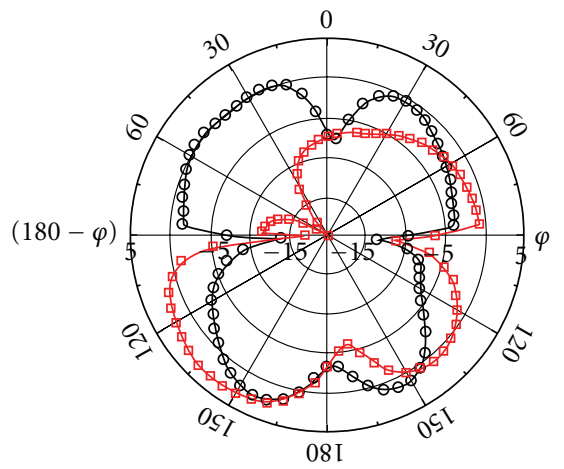

(f)

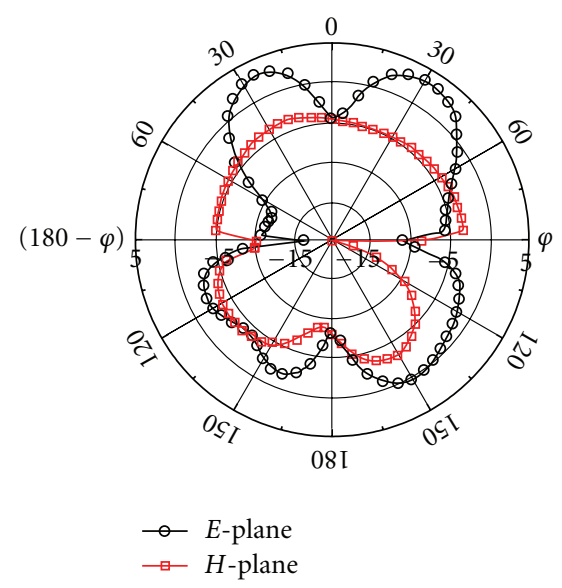

(g)

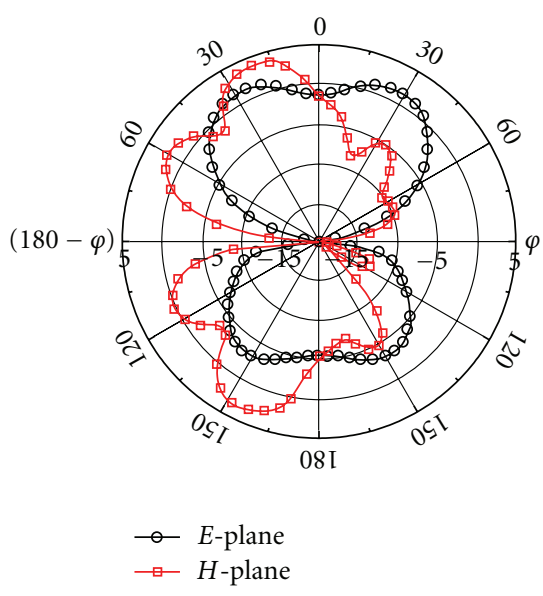

(h)

Figure 10: Simulated radiation patterns of the proposed antenna-(a) $f=1.95 \mathrm{GHz}$, (b) $f=2.5 \mathrm{GHz}$, (c) $f=3.8 \mathrm{GHz}$, (d) $f=5.0 \mathrm{GHz}$, (e) $f=6.5 \mathrm{GHz}$, (f) $f=8.0 \mathrm{GHz}$, (g) $f=9.8 \mathrm{GHz}$, and (h) $f=10.4 \mathrm{GHz}$.

\section{Antenna Fabrication and Measurement}

The antenna has been fabricated by the following process and the fabricated antenna is shown in Figures 6(a)-6(d).

4.1. Fabrication Process. For the fabrication process, see Figure 13.

4.2. Return Loss and Other Characteristics. The measured return loss as shown in Figure 7 is $-31 \mathrm{~dB}$ at $6.45 \mathrm{GHz}$ and from RL curve, the bandwidth obtained for $\mathrm{RL} \leq-10 \mathrm{~dB}$ is $8.74 \mathrm{GHz}$. The results obtained from the measurement has a VSWR (Figure 8) lower than $2\left(\mathrm{~S}_{11} \leq-10 \mathrm{~dB}\right)$ for the entire frequency range from $1.85 \mathrm{GHz}$ to $10.54 \mathrm{GHz}$, and the maximum impedance bandwidth of $129 \%$ is obtained centered at $6.45 \mathrm{GHz}$. A good agreement is observed between the measured and simulated data.

One can observe a small difference between measured and simulated data at different frequencies. This might be due to other unknown parasitic effects which are not 


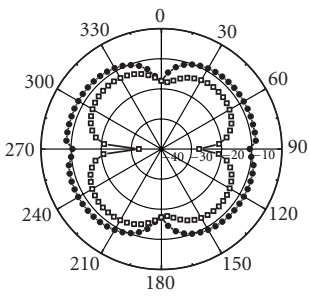

(a)

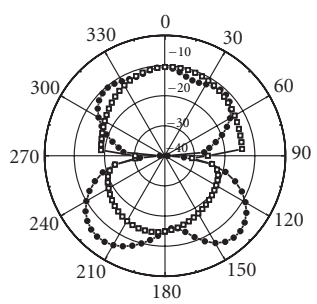

(e)

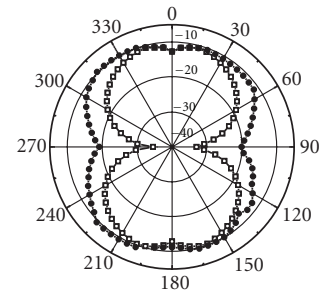

(b)

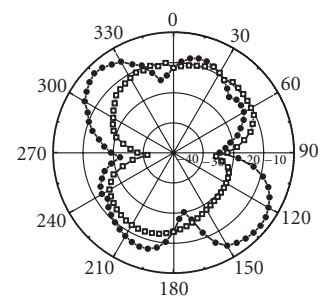

(f)

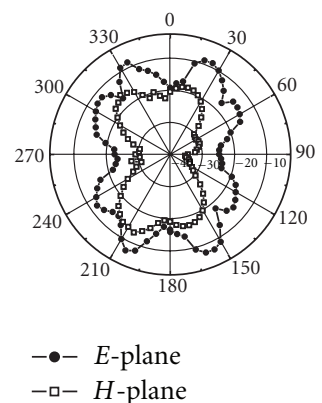

(i)

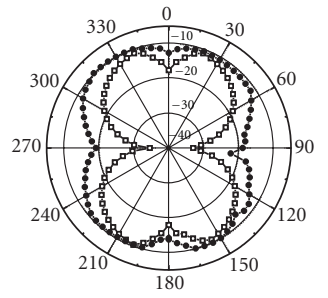

(c)

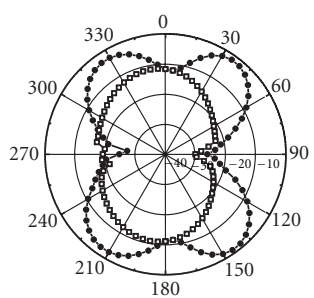

(g)

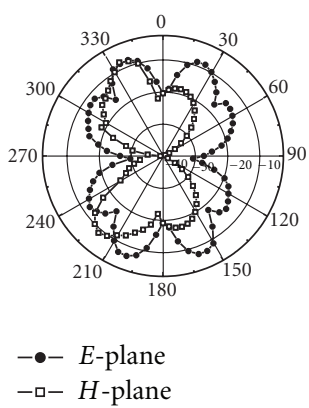

(j)

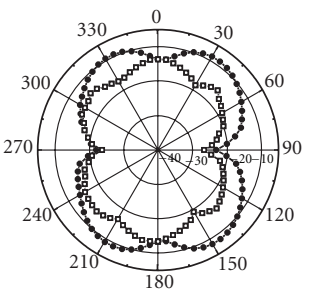

(d)

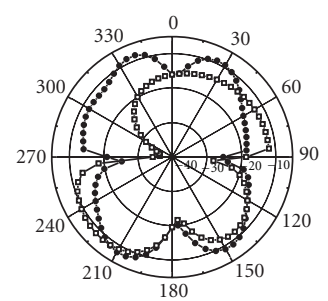

(h)

FiguRE 11: Measured radiation patterns of the proposed antenna-(a) $f=1.95 \mathrm{GHz}$, (b) $f=2.4 \mathrm{GHz}$, (c) $f=3.5 \mathrm{GHz},(\mathrm{d}) f=4.5 \mathrm{GHz}$, (e) $f=5.5 \mathrm{GHz}$, (f) $f=6.5 \mathrm{GHz}$, (g) $f=7.5 \mathrm{GHz}$, (h) $f=8.8 \mathrm{GHz}$, (i) $f=9.5 \mathrm{GHz}$, and (j) $f=10.4 \mathrm{GHz}$.

considered in the simulation. Since the soldering is not done with a machine on the $\mathrm{PCB}$, positional errors might give rise to the discrepancy.

Measurements of antenna gain for UWB band across frequencies from $1 \mathrm{GHz}$ to $11.4 \mathrm{GHz}$ are investigated. The measured peak gain in the $y-z$ (E-plane) plane across the frequency bands of interest is shown in Figure 9. A small difference between measured and simulated data of curve at different frequencies is observed. This difference may be due to the error occurred as a result of fabrication.

4.3. Radiation Pattern. The microstrip patch antenna radiates normally to its patch surface. So the elevation pattern gain for $\varphi=0$ and $\varphi=90$ degrees is important for the measurement. Figures 10 and 11 show the simulated and measured $E$-plane and $H$-plane patterns at different frequencies. The maximum gain is obtained in broadside direction and the peak gain at design frequencies varies from $0.8 \mathrm{dBi}$ to $3.9 \mathrm{dBi}$.

From measured and simulated radiation pattern (shown in Figures 10 and 11), it is observed that the ripples become more prominent at higher frequencies since the antenna operates in higher order modes instead of the typical monopole mode.

The simulated results of current distribution (front and back view) on the patch surface with and without slots are illustrated stepwise in Figure 12.

\section{Conclusion}

A new approach of slotted antenna fed by a $50 \Omega$ ECPW for UWB applications was presented. Wide bandwidth of $129 \%$ was achieved by using inverted G'-shaped tuning slots placed at the back conductor. The proposed slotted ECPW microstrip antenna is electrically small and suitable to be handled easily. From the results, it is observed that the maximum gain obtained in the broadside direction. The measured value of RL and VSWR fairly tallied with the simulated results. In this work, the B.W of $8.74 \mathrm{GHz}$ has been achieved by the proposed antenna structure. The impedance bandwidth of VSWR lower than $2\left(S_{11} \leq-10 \mathrm{~dB}\right)$ for the entire UWB range $(3.1 \mathrm{GHz}$ to $10.6 \mathrm{GHz}$ ) has been achieved with simple ECPW antenna structure. A prototype antenna has been designed, simulated, optimized, and measured for 


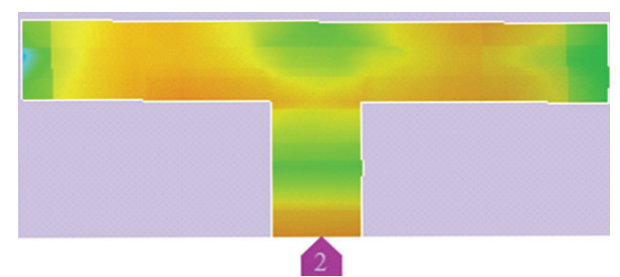

(a)

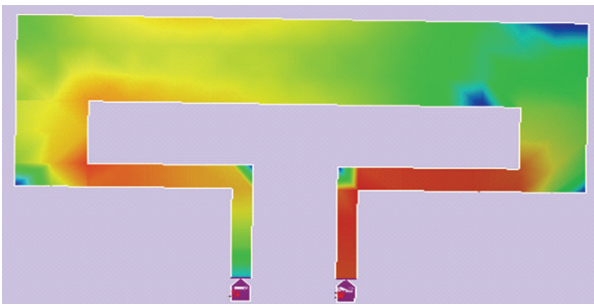

(b)

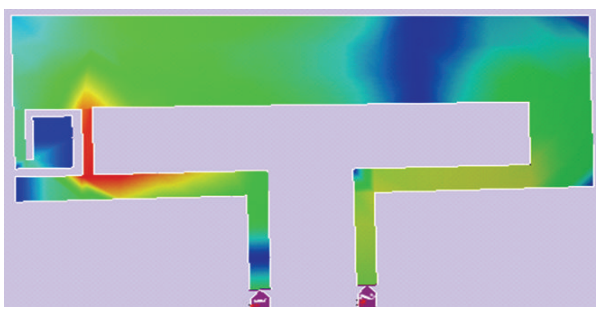

(c)

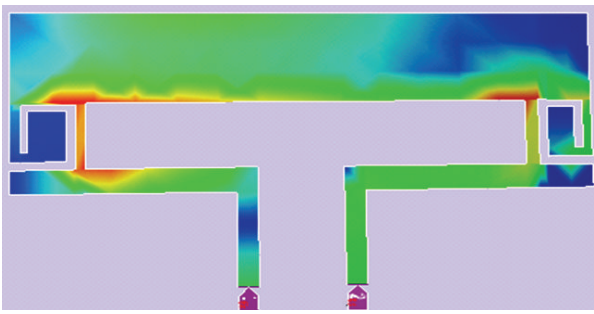

(d)

FIgURE 12: Current distribution. (a) Front view and back, (b) without slot, (c) with slot $\mathrm{A}$, (d) with slot (A and $\left.\mathrm{A}^{\prime}\right)$.

UWB operation. The novel antenna promotes impedance bandwidth and radiation which offers good radiation pattern and has a favorable field gain across the matching band as a desirable feature for UWB applications. The proposed antenna has a simple and effective feeding structure which is suitable for use in UWB applications. The fabrication process is simple and has a low cost. The antennas have demonstrated good performance in terms of VSWR, input impedance, current distribution, radiation pattern, gain, and efficiency.

\section{Acknowledgment}

The authors like to acknowledge Bengal Engineering and Science University, Shibpur, India, for providing necessary support during this work.

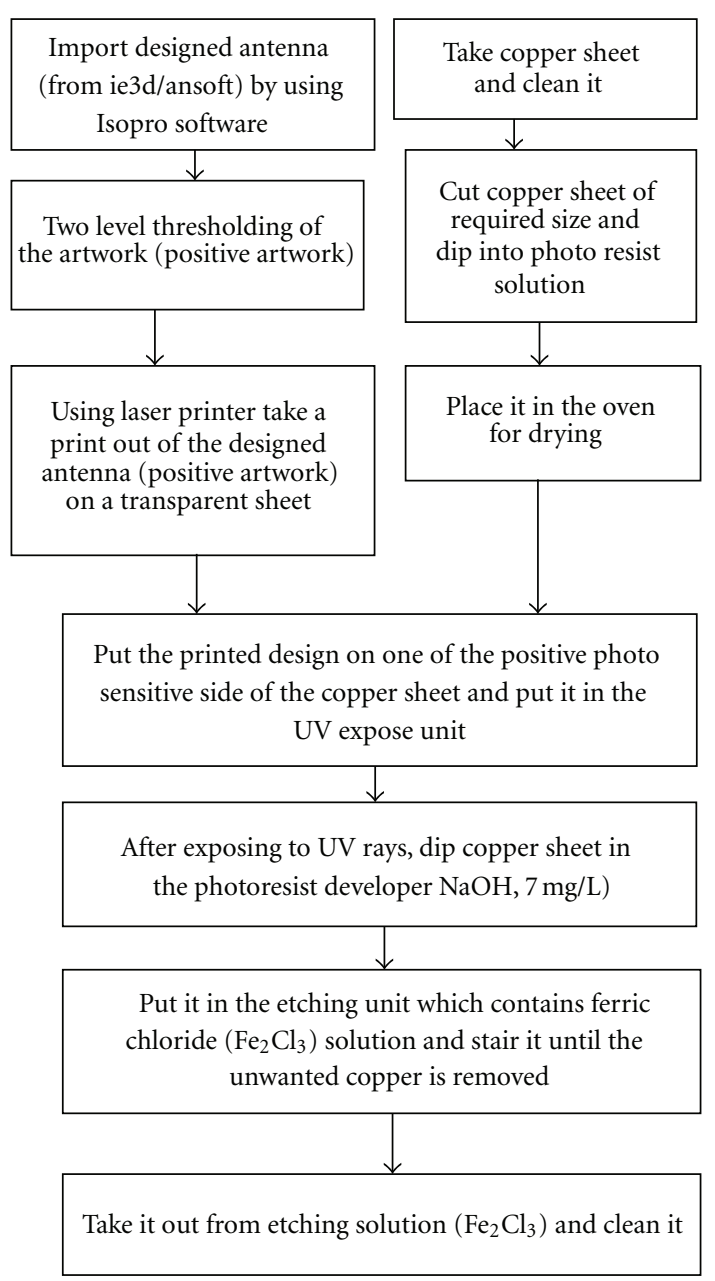

FigURE 13

\section{References}

[1] J. D. McKinney and A. M. Weiner, "Compensation of the effects of antenna dispersion on UWB waveforms via optical pulse-shaping techniques," IEEE Transactions on Microwave Theory and Techniques, vol. 54, no. 4, pp. 1681-1686, 2006.

[2] "FCC first report and order on ultra-wideband technology," 2002.

[3] K. Y. Yazdandoost and R. Kohno, "Ultra wideband antenna," IEEE Communications Magazine, vol. 42, no. 6, pp. S29-S32, 2004.

[4] A. C. Shagar and R. S. D. Wahidabanu, "New design of CPWfed rectangular slot antenna for ultra wideband applications," International Journal of Electronics Engineering, vol. 2, no. 1, pp. 69-73, 2010.

[5] S. Barbarino and F. Consoli, "Study on UWB and SWB planar slot antennas with different stub shapes," Microwave and Optical Technology Letters, vol. 53, no. 7, pp. 1528-1532, 2011.

[6] Y. Ranga, K. P. Esselle, and A. R. Weily, "Compact ultrawideband CPW-fed printed semicircular slot antenna," Microwave and Optical Technology Letters, vol. 52, no. 10, pp. 2367-2372, 2010. 
[7] D. Parkash and R. Khanna, "A compact wideband CPW fed hash-shape slot monopole antenna for wireless communication applications," Journal of Punjab Academy of Sciences, vol. 5-6, pp. 5-9, 2010.

[8] Y. F. Ruan, Y. X. Guo, K. W. Khoo, and X. Q. Shi, "Compact wideband antenna for wireless communications," IET Microwaves, Antennas and Propagation, vol. 1, no. 3, pp. 556560, 2007.

[9] T. G. Ma and C. H. Tseng, "An ultrawideband coplanar waveguide-fed tapered ring slot antenna," IEEE Transactions on Antennas and Propagation, vol. 54, no. 4, pp. 1105-1110, 2006.

[10] S. Hu, H. Chen, C. L. Law et al., "Backscattering cross section of ultrawideband antennas," IEEE Antennas and Wireless Propagation Letters, vol. 6, pp. 70-73, 2007.

[11] M. A. Peyrot-Solis, G. M. Galvan-Tejada, and H. JardonAguilar, "State of the art in ultra-wideband antennas," in Proceedings of the 2nd International Conference on Electrical and Electronics Engineering (ICEEE '05) and 11th Conference on Electrical Engineering (CIE '05), pp. 101-105, Mexico City, Mexico, September 2005.

[12] M. T. Islam, M. N. Shakib, and N. Misran, "Broadband E$\mathrm{H}$ shaped microstrip patch antenna for wireless systems," Progress in Electromagnetics Research, vol. 98, pp. 163-173, 2009.

[13] K. P. Ray and Y. Ranga, "Ultrawideband printed elliptical monopole antennas," IEEE Transactions on Antennas and Propagation, vol. 55, no. 4, pp. 1189-1192, 2007.

[14] J. I. Kim and Y. Jee, "Design of ultrawideband coplanar waveguide-fed Li-shape planar monopole antennas," IEEE Antennas and Wireless Propagation Letters, vol. 6, pp. 383-387, 2007.

[15] M. A. Peyrot-Solis, J. A. Tirado-Mendez, and H. JardonAguilar, "Design of multiband UWB planarized monopole using DMS technique," IEEE Antennas and Wireless Propagation Letters, vol. 6, pp. 77-79, 2007.

[16] H. M. Jafari, M. J. Deen, S. Hranilovic, and N. K. Nikolova, "A study of ultrawideband antennas for near-field imaging," IEEE Transactions on Antennas and Propagation, vol. 55, no. 4, pp. 1184-1188, 2007.

[17] T. N. Chang and J. H. Jiang, "Meandered T-shaped monopole antenna," IEEE Transactions on Antennas and Propagation, vol. 57, no. 12, pp. 3976-3978, 2009.

[18] T. H. Kim and D. C. Park, "CPW-fed compact monopole antenna for dual-band WLAN applications," Electronics Letters, vol. 41, no. 6, pp. 291-293, 2005.

[19] W. C. Liu, "Broadband dual-frequency CPW-FED antenna with a cross-shaped feeding line for WLAN application," Microwave and Optical Technology Letters, vol. 49, no. 7, pp. 1739-1744, 2007.

[20] W. C. Liu, "Broadband dual-frequency cross-shaped slot CPW-FED monopole antenna for wlan operation," Microwave and Optical Technology Letters, vol. 46, no. 4, pp. 353-355, 2005.

[21] Y. C. Lee, S. C. Lin, and J. S. Sun, "CPW-fed UWB slot antenna," in Proceedings of the 2006 Asia-Pacific Microwave Conference (APMC '06), pp. 1636-1639, December 2006.

[22] M. A. Saed, "Broadband CPW-fed planar slot antennas with various tuning stubs," Progress in Electromagnetics Research, vol. 66, pp. 199-212, 2006.

[23] J. Wang, H. Zhang, W.-H. Chen, and C. Sheng, "Design and application of a novel CB-CPW structure," Progress in Electromagnetics Research, vol. 4, pp. 133-142, 2008.
[24] K. Hettak, M. G. Stubbs, K. Elgaid, and I. G. Thaine, "Design and characterization of elevated CPW and thin film microstrip structures for millimeter-wave applications," in Proceedings of the European Microwave Conference, vol. 2, p. 4, Paris, France, 2005.

[25] F. Aghamoradi, I. McGregor, and K. Elgaid, "Performance enhancement of millimetre-wave resonators using elevated CPW," Electronics Letters, vol. 45, no. 25, pp. 1326-1328, 2009.

[26] S. Lee, S. Jung, and H. Y. Lee, "Ultra-wideband CPW-tosubstrate integrated waveguide transition using an elevatedCPW section," IEEE Microwave and Wireless Components Letters, vol. 18, no. 11, pp. 746-748, 2008.

[27] M. Forman and Z. Popovic, "A K-band ground-backed CPW balanced coupler and integrated antenna feed," in Proceedings of the European Microwave Conference, October 2000.

[28] S. Hofschen and I. Wolff, "Simulation of an elevated coplanar waveguide using 2-D FDTD," IEEE Microwave and Guided Wave Letters, vol. 6, no. 1, pp. 28-30, 1996.

[29] I. McGregor, F. Aghamoradi, and K. Elgaid, "An approximate analytical model for the quasi-static parameters of elevated CPW lines," IEEE Transactions on Microwave Theory and Techniques, vol. 58, no. 12, pp. 3809-3814, 2010.

[30] F. Aghamoradi, I. McGregor, and K. Elgaid, "Performance enhancement of millimetre-wave resonators using elevated CPW," Electronics Letters, vol. 45, no. 25, pp. 1326-1328, 2009.

[31] S. H. Jeong, S. J. Yoon, J. G. Yook, S. G. Lee, and Y. J. Kim, "Elevated-CPW for high-speed digital interconnects," in Proceedings of the IEEE Antennas and Propagation Society International Symposium, pp. 541-544, usa, July 2001.

[32] IE3D User's Manual, Release 11, Zeland Software, Inc., Fremont,Calif, USA, 2005.

[33] K. P. Ray and Y. Ranga, "Printed rectangular monopole antennas," in Proceedings of the IEEE Antennas and Propagation Society International Symposium (APS '06), pp. 1693-1696, July 2006. 

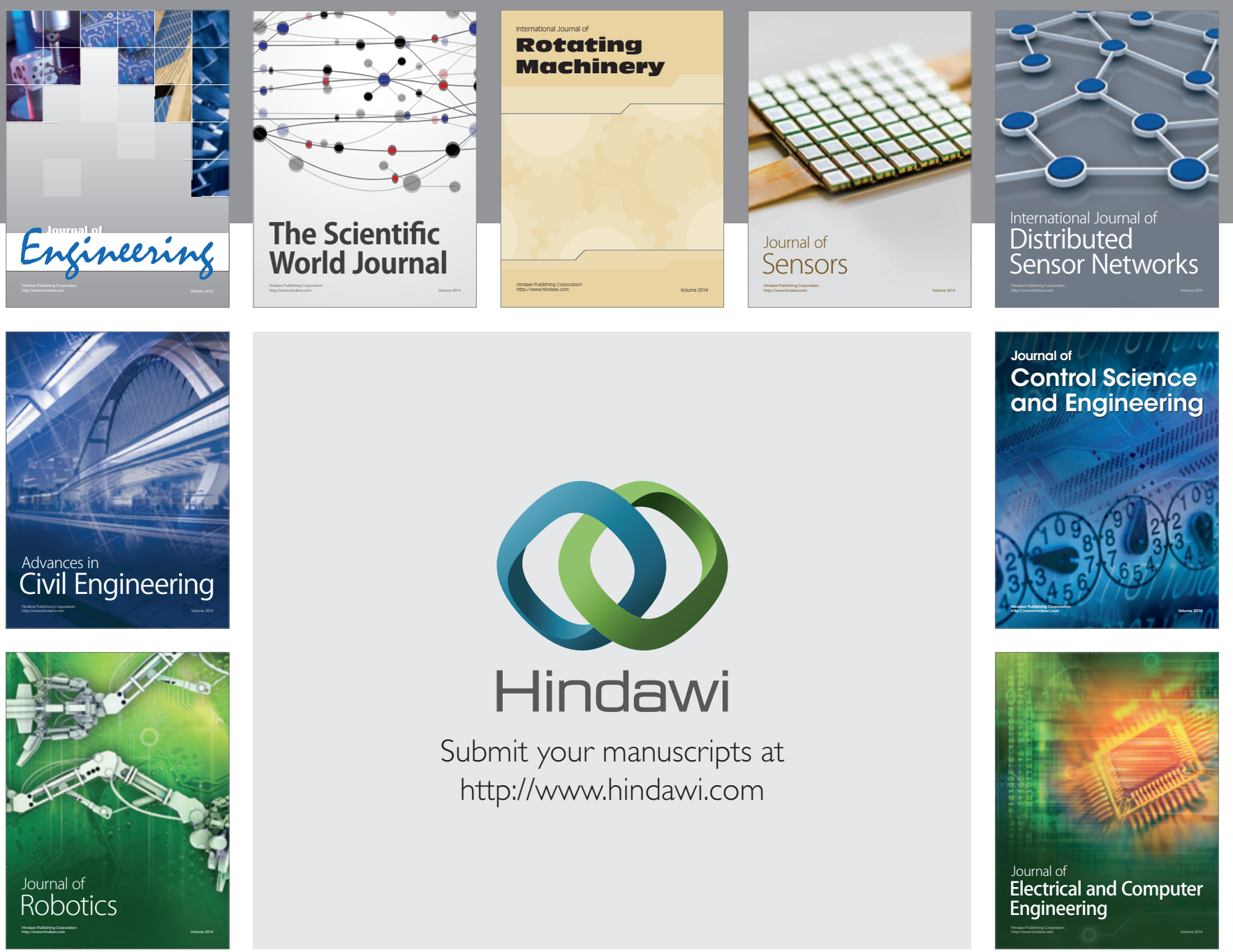

Submit your manuscripts at

http://www.hindawi.com
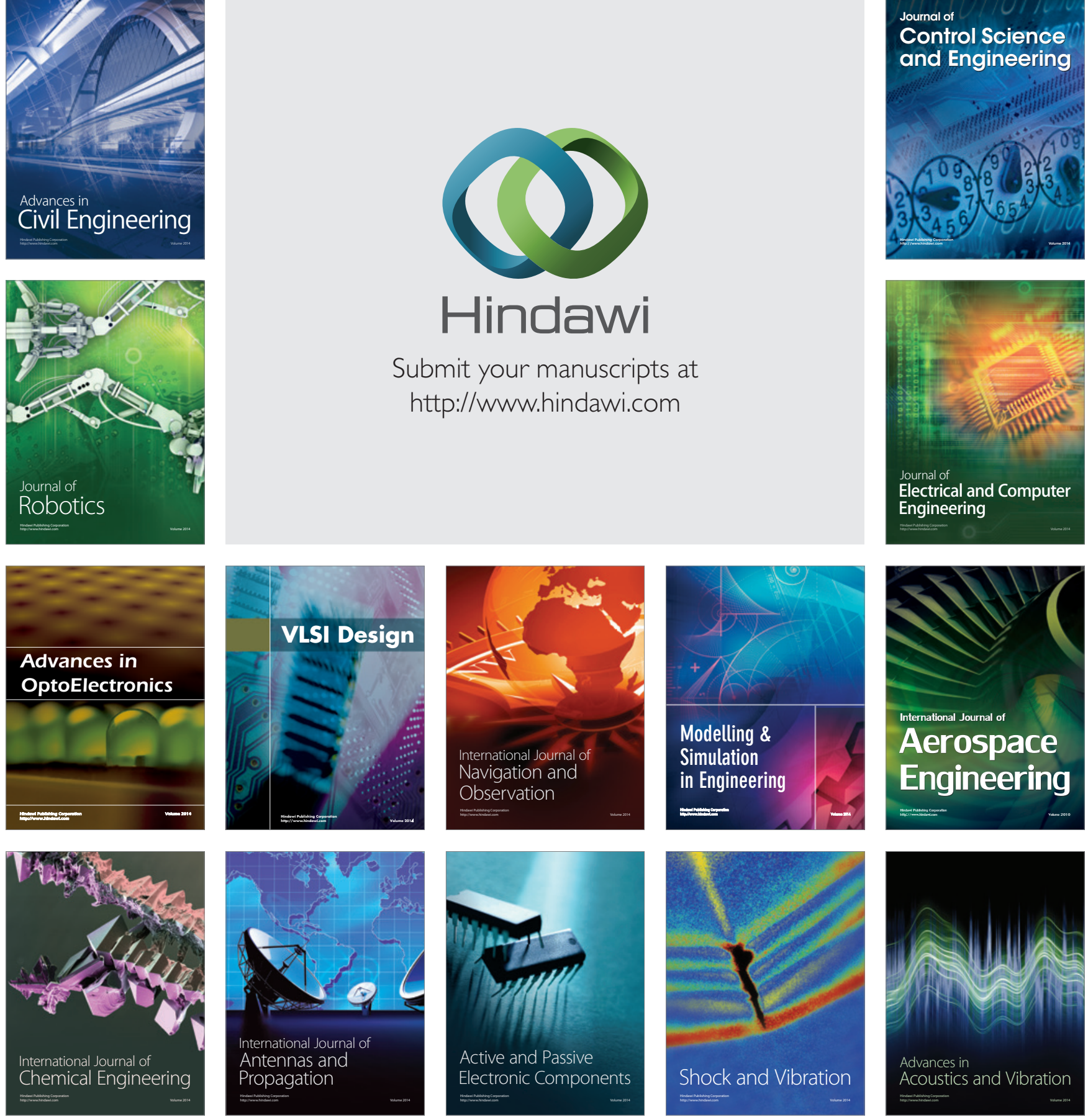